\title{
Maternal literacy and health behavior: a Nepalese case study
}

\section{Citation}

LeVine, Robert A, Sarah E LeVine, Meredith L Rowe, and Beatrice Schnell-Anzola. 2004.

"Maternal Literacy and Health Behavior: a Nepalese Case Study." Social Science \& Medicine 58 (4): 863-877.

\section{Published Version}

doi:10.1016/S0277-9536(03)00261-2

\section{Permanent link}

http://nrs.harvard.edu/urn-3:HUL.InstRepos:13041219

\section{Terms of Use}

This article was downloaded from Harvard University's DASH repository, and is made available under the terms and conditions applicable to Other Posted Material, as set forth at http:// nrs.harvard.edu/urn-3:HUL.InstRepos:dash.current.terms-of-use\#LAA

\section{Share Your Story}

The Harvard community has made this article openly available.

Please share how this access benefits you. Submit a story.

\section{Accessibility}




\title{
Maternal literacy and health behavior: a Nepalese case study
}

\author{
Robert A. LeVine*, Sarah E. LeVine, Meredith L. Rowe, \\ Beatrice Schnell-Anzola
}

Graduate School of Education, Harvard University, Roy E. Larsen Hall, Appian Way, Cambridge, MA 02138, USA

\begin{abstract}
This article addresses the question of whether literacy could be mediating the relationships of schooling to maternal health behavior in populations undergoing demographic transition. Recent studies in which literacy was directly assessed suggest a literacy pathway to demographic change. The literacy skills of 167 urban and rural mothers of school-aged children in Lalitpur District of the Kathmandu Valley of Nepal were assessed by tests of reading comprehension, academic language proficiency, health media skills and health narrative skill, as part of studies in the urban and rural communities that included a maternal interview and ethnographic fieldwork on the contexts of family life, health care and female schooling. Regression analysis of the data indicates the retention of literacy skills in adulthood and their influence on health behavior; ethnographic evidence shows that selective bias in school attainment does not account for the results. Further direct assessment studies are recommended.
\end{abstract}

(C) 2003 Elsevier Science Ltd. All rights reserved.

Keywords: Nepal; Women; Education; Literacy; Health behavior; Child survival

\section{Introduction}

Is literacy involved in the processes through which schooling alters maternal health behavior and reduces the risks to child survival? In this article we seek an answer among rural and urban women in the Kathmandu Valley of Nepal by directly assessing the literacy and language skills they acquired in school. There is a large body of evidence linking women's school attainment to birth and death rates and the utilization of health and contraceptive services in developing countries (Diamond, Newby, \& Varle, 1999), raising questions about the relevance of literacy. The few demographic and health surveys seeking to answer these questions through the direct assessment of maternal literacy (as opposed to assessing it indirectly through self-reports or scores imputed from school attainment) have suggested

\footnotetext{
*Corresponding author.

E-mail address: bob_levine@gse.harvard.edu (R.A. LeVine).
}

a potential literacy pathway from schooling to health and fertility outcomes.

In a national survey based on the World Bank's Living Standards Measurement Study, 1495 Moroccan mothers of children 5 years old or younger were given a battery of tests covering health knowledge, general knowledge (actually a functional literacy test), numeracy and literacy in French and Arabic. Each child's health was assessed through height for age (an inverse measure of "stunting" or chronic malnutrition, indicating ill health) (Glewwe, 1997, 1999). Mother's schooling predicted child height for age with other socioeconomic factors controlled, and so did functional literacy in Arabic. Glewwe (1999) also found that maternal health knowledge was the best predictor of height, concluding that "education improves child health primarily by increasing health knowledge," even though Moroccan schools do not teach such knowledge directly; instead, children acquire literacy and numeracy skills in school, which they then use to obtain health knowledge outside of school (Glewwe, 1999, p. 151). Thomas (1999) 
analyzed data from 778 black South African women aged 15-49 years who participated in the 1993 survey of the Project for Statistics for Living Standards and Development of South Africa, which covered 9000 households. These women were given a Literacy Assessment Module (LAM) testing three basic skills: reading comprehension, listening comprehension, practical mathematics and computational skill. Regression analysis showed schooling to be a strong predictor of children ever born (CEB), controlling for age and ruralurban residence: Each additional year of school attendance is associated with 0.12 fewer children. Reading comprehension was an apparent vehicle of this influence: The average woman who answered all six comprehension questions correctly had nearly half a child less than a woman who failed to answer any of the questions correctly, and controlling for income did not alter this finding. Thomas (1999) concludes, "Women with better comprehension skills may be better able to access and assimilate information in the community. They may thus be likely to be better informed than their peers and therefore better able to use community services effectively" (p. 172).

An analysis of Guatemalan data by Khandke, Pollitt, and Gorman (1999) involved 266 children and their mothers who were participants in a longitudinal supplementation study conducted by the Institute of Nutrition in Central America and Panama (INCAP) from 1969 to 1977 in four Spanish-speaking villages of rural eastern Guatemala. The children were monitored weekly for respiratory illness during the first 4 years of life; mothers took a literacy test based on local materials (Gorman \& Pollitt, 1997). Maternal schooling ranged from 0 to 6 years, with a mean of 1.34 and a standard deviation of 1.39. Khandke, Pollitt and Gorman found that the children of mothers with 4-6 years of schooling had less respiratory illness than those whose mothers had 1-3 years of schooling (with socioeconomic variables controlled) and that a mother's literacy score was a significant predictor of her child's respiratory illness at 4 years of age, in a regression model that controlled for socioeconomic status and maternal school attainment.

Thus evidence from Morocco, South Africa and Guatemala has shown that when literacy testing was added to large-scale surveys or surveillance studies, the results suggested a pathway from women's schooling to demographic or health outcomes through literacy and health information. These studies provide some initial plausibility for further consideration of how literacy might be mediating the influence of school experience on women's reproductive and health behavior.

In the Project on Maternal Schooling at the Harvard Graduate School of Education, we have been investigating the links between women's schooling and reproductive change in Mexico, Nepal, Zambia and Venezuela.

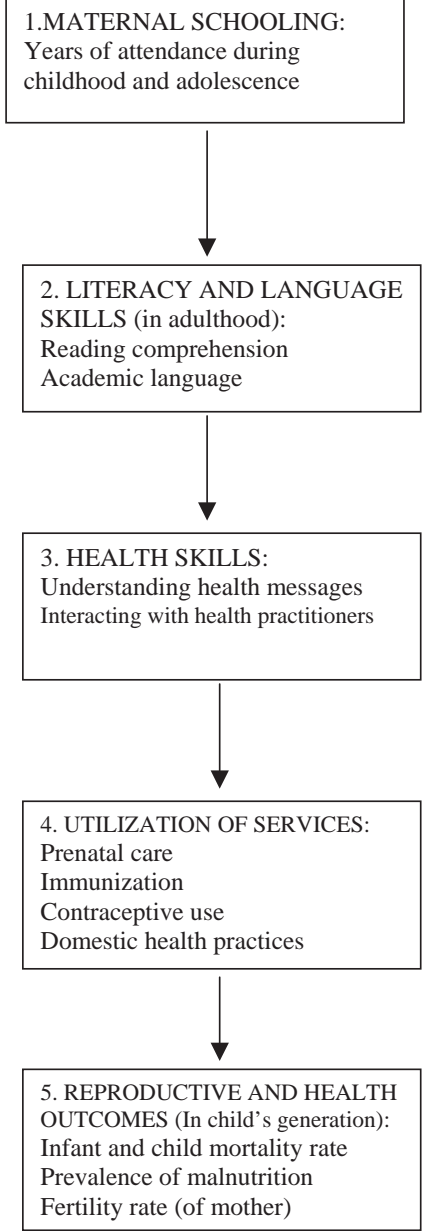

Fig. 1. Hypothetical influences of maternal literacy on health and child development.

We identified four plausible pathways (aspirations, skills, identity/empowerment and models of learning and teaching) through which the schooling of women in developing countries might affect demographic change (LeVine, LeVine, \& Schnell, 2001). Although all four are probably implicated in the processes of school influence on maternal behavior, we have increasingly focused our research on the skill pathway, particularly proficiency in literacy and language skills acquired in school, as illustrated in Fig. 1.

Our field studies of urban and rural sites have combined ethnographic fieldwork with surveys and literacy testing in micro-communities located in subnational regions (urban areas, provinces or districts) for which available evidence had previously shown associations between women's schooling and changing levels of child survival and fertility. Six sites have been studied, including rural and urban sites in Mexico and Nepal and 
urban sites in Zambia and Venezuela (LeVine et al., 1991, 1994, 2001; Joshi, 1994; Stuebing, 1997; Dexter, LeVine, \& Velasco, 1998).

We deliberately selected micro-communities in which child-bearing women with a wide range of school attainment levels (none, incomplete primary, complete primary, post-primary) were living in the same lowincome neighborhoods or rural communities. There was no attempt to select a community representative of the national population; on the contrary, the research sites were more advanced in women's schooling than many other local populations in their respective countries at the time we studied them, but in a national context of continuing school expansion, communities like them were increasing in frequency. This research design permits an examination of schooling as a continuous variable at high as well as low levels of "dosage", while controlling for at least some other socioeconomic variables (e.g., community environment, proximity to health facilities). By replicating this study in maximally diverse sites in the developing world, we hoped to identify similarities and differences in the processes by which schooling affects reproductive and health behavior and to provide tentative estimates of causal pathways that could be investigated more definitively in large-scale, longitudinal and quasi-experimental studies.

Our studies in rural Mexico (Dexter et al., 1998), urban Zambia (Stuebing, 1997) and urban Venezuela (LeVine et al., 2001) showed maternal school attainment during childhood and adolescence to be strongly and robustly related to adult literacy skills and comprehension of health messages. This body of evidence, together with the previous field study by Joshi (1994) in rural Nepal, provided a basis for the more extensive Nepalese study presented in this article.

\section{Demographic change in Nepal}

Nepal, located in the Himalayas between India and Tibet, is a low-income, predominantly rural, country of about 23 million people. It was isolated by deliberate policy until 1951, and its socioeconomic development has been slow for much of the last 50 years. A demographic transition is nevertheless under

Table 1

Indicators of demographic transition in Nepal, 1971-1996

\begin{tabular}{lcccc}
\hline & 1971 & 1981 & 1991 & 1996 \\
\hline Infant mortality rate & 172 & 117 & 97 & 93 \\
Total fertility rate & 6.3 & 6.3 & 5.6 & 4.6 \\
\hline
\end{tabular}

Source: Pradhan et al. (1997). way, as shown in Table 1 for the 25 years from 1971 to 1996. The infant mortality rate declined by $46 \%$ over the period, and the total fertility rate dropped $27 \%$ from 1981 to 1996 . The 1996 levels are still high by world standards, but demographic analysts expect the declining trends to continue (Thapa, Neidell, \& Dahal, 1998). Female school attendance has been increasing, particularly in recent years and particularly in the Kathmandu Valley where urban development is concentrated. Evidence from surveys of women age 15-49 years shows associations of maternal schooling with reductions in fertility and child mortality (Luther \& Thapa, 1999; Pradhan, Aryal, Regmi, Ban, \& Govindaswamy, 1997; Retherford \& Thapa, 1998; Thapa, 1996).

Multivariate analyses of national survey data on Nepal indicate that maternal schooling is associated with child survival and fertility even when socioeconomic variables are controlled. Thapa's (1996) path analysis of 1991 data on the 75 districts of Nepal shows a path from the two variables of maternal literacy (indirectly assessed) and access to health care, through health-care utilization, that accounts for $44 \%$ of the district-level variation in infant mortality, and the Luther and Thapa (1999) analysis of the 1996 Nepal Family Health Survey (NFHS) also shows some significant effects of maternal schooling and prenatal care on child mortality with other factors controlled. Analysis of fertility data from the same 1996 survey by Retherford and Thapa (1998) indicates an independent effect of a woman's schooling on her fertility. Thus even though the number of schooled women in national surveys of Nepal is small, the "educational differentials" familiar in the demographic patterns of other developing countries have been replicated in evidence from the 1990s in Nepal.

The evidence, particularly from the 1996 NFHS, also points to several pathways through which schooling might influence child survival and fertility among Nepalese women - rising age at marriage, more frequent use of maternal and child health services and contraception, and greater exposure to public health as well as family planning messages in the mass media. Luther and Thapa (1999), for example, show that use of prenatal care (number of visits, tetanus immunization) predicts lower infant mortality in the NFHS sample with socioeconomic factors controlled, though their analysis does not attempt to forge a link with schooling. The NFHS report does show strong (unadjusted) associations of female school attainment with some prenatal care (as opposed to none), with seeing a doctor for prenatal care (as opposed to another kind of health care provider), and with getting two or more tetanus toxoid injections (Pradhan et al., 1997, pp. 111-115). The report also shows that although more than $90 \%$ of the Nepalese women surveyed had heard of 
using jeevan jal (Nepali for oral rehydration salts or ORS) for a child's diarrhea, only $23 \%$ of unschooled mothers whose children had a bout of diarrhea in the last 2 weeks had used ORS, but $36 \%$ of those with some schooling had. Furthermore, only $30.8 \%$ of the unschooled reported mixing it correctly, while about $45 \%$ of those with schooling had done so (Pradhan et al., 1997, pp. 130-137). (These are also unadjusted associations.)

As for fertility, its link with schooling so far seems to be through the later age at marriage of women with schooling, although contraceptive use is also related to schooling (Pradhan et al., 1997, pp. 58-59). There are strong (unadjusted) associations between women's school attainment and having heard a family planning program on the radio or read a family planning message in print (Pradhan et al., 1997, p. 68-73). Nepal as a national population is at an early stage of demographic transition and expansion of women's schooling, but familiar trends linking school experience with child survival and fertility (and their usual concomitants) are already evident.

We are not suggesting that women's schooling was a major determinant of the national declines in mortality and fertility displayed in Table 1, which occurred largely when school experience was still a rarity among childbearing women in Nepal. We are proposing that-in Nepal as elsewhere - as schools become more common features of childhood experience, and as health and family planning clinics become more common in adult women's lives, the developing connections between bureaucratized education, i.e. schools, and other bureaucratic services contribute to demographic transition. In Nepal these connections are most likely to have developed in the Kathmandu Valley and to be accessible to investigation there.

\section{Lalitpur district}

Approximately $85 \%$ of the people of Nepal live in its rural areas. Kathmandu is the only major urban center, with a population of about 530,000 (together with its metropolitan area, over a million), and is not only the capital but also the center of Nepal's commerce, industry, road and air networks and media of communication, with its greatest concentration of hospitals, schools (public and private) and religious institutions (Hindu temples, Buddhist stupas and monasteries, Christian churches). The area surrounding the city, known as the Kathmandu Valley and located between the foothills of the Himalayas, is a relatively rich agricultural region with towns and villages that benefit from access to the trade, employment and manifold services of the urban center. With no railway and an inadequate road network, the rest of Nepal is isolated from Kathmandu and, with the exception of a few districts to the west and south, is much less developed economically than the valley. There is thus a sharp contrast in wealth and development within Nepal between the favored Kathmandu Valley and most other regions of the country.

In the Kathmandu Valley, school attendance, including that of females, is higher than other regions in Nepal and infant mortality relatively low. We selected Lalitpur District (1991 population: 257,000), adjacent to the city of Kathmandu, for our community-level studies of 1996-1998. Lalitpur consists of an urban area called Patan (an independent monarchy until 1769), just across the Bagmati River from Kathmandu itself and effectively part of the city, and a rural region of 41 towns and villages. One of our community-level studies was conducted in urban Patan, the other 8 miles away in the rural area of Godavari, which had been studied by Arun Joshi (1994) in 1988-1990.

In 1991, Lalitpur District had an infant mortality rate of 51 compared with 93 for Nepal as a whole (Thapa, 1996), and $32 \%$ of ever-married women age $15-49$ years had ever attended school compared with $14 \%$ for Nepal as a whole. These figures come from the 1991 Nepal Fertility, Family Planning and Health Survey (NFFPHS or NFS), which covered some 25,000 women across the country, 291 from Lalitpur District, providing baseline data for our own research. (Stash \& Hannum, 2001, have analyzed the school attainment data in this national data set and provided a description of the sampling procedures, pp. 362-363.)

The Lalitpur District data (on all 117 women in the 1991 survey who reported a birth in the last 5 years) show maternal schooling to be negatively correlated with CEB (partial $r=-0.30, p<0.001$, controlling for age) and positively associated with the use of health services during pregnancy, suggesting an influence of women's schooling on demographic change at that time. Table 2 shows that maternal schooling, controlling for other socioeconomic factors (age, childhood and adult SES, husband's level of schooling, urban or rural residence and caste), is a significant predictor of a medicalized pregnancy variable (comprised of prenatal care by a doctor, tetanus injections, hospital delivery and delivery by a doctor). Age, adult SES and urban residence are also significant predictors in this model. Taken together, these variables explain approximately $55 \%$ of the variation in mothers' scores on medicalized pregnancy.

These results point to an effect of schooling on maternal health behavior during pregnancy and childbirth and raise questions about the pathway through which the effect operates. The community-level studies we conducted in Lalitpur District from 1996 to 1998 were designed to investigate whether literacy skills were involved in that pathway. 
Table 2

Regression model predicting medicalized pregnancy in Lalitpur District, 1991 Nepal Fertility, Family Planning and Health Status Survey $(n=117)$

\begin{tabular}{ll}
\hline Predictors & $\beta$ coefficient (SE) \\
\cline { 2 - 2 } & Medicalized pregancy \\
\hline Intercept & $2.41^{* * *}(0.60)$ \\
Maternal schooling & $0.10^{* *}(0.03)$ \\
Age & $-0.07^{* *}(0.02)$ \\
Childhood residence & $-0.28(0.53)$ \\
Current SES & $0.20^{*}(0.10)$ \\
Husband's schooling & $0.005(0.03)$ \\
Urban/rural & $1.34 *(0.55)$ \\
Caste & $0.10(0.11)$ \\
$R^{2}$ stat. (error d.f.) & $0.5495(109)$ \\
\hline$* p<0.05$. & \\
$* * p<0.01$. & \\
$* * * p<0.001$. & \\
dichedicalized pregnancy is a composite (sum) of several \\
woman, for her last birth, received: prenatal care by doctor, \\
tetanus injection during pregnancy, hospital delivery and \\
doctor delivery.
\end{tabular}

\section{The 1996-1998 studies in Lalitpur District}

The fieldwork in Patan and Godavari was carried out from October of 1996 to June of 1998 by Sarah E. LeVine and a team of collaborators. The research in both sites included ethnographic study of the social and cultural contexts of women's and children's lives, a census of mothers and children, and the drawing of samples for literacy testing and interviewing.

Like the Kathmandu Valley, in general, Lalitpur District is complex in its social, cultural, religious and linguistic composition, reflecting a history of ancient settlement and conquest. The urban sample was drawn from a single neighborhood in central Patan that is largely inhabited by Buddhist Newars whose ancestors have lived there for centuries. Their native language is Newari, a Tibeto-Burman language, although many also speak the national language, Nepali, which is Sanskritic. Newars are segmented into their own castes, i.e. ranked endogamous occupational groups, separate from the caste distinctions officially imposed by the Nepali Hindu monarchy in the 19th century. We sampled from four upper and middle castes, the only ones in this neighborhood of Patan that contained significant numbers of married women who had attended school. Even in this population, the two highest castes of Buddhists, Vajracaryas and Shakyas, had been slow to send children to school, as their sons could support themselves in traditional occupations (as household priests and goldsmiths or icon makers, respectively) without gaining school credentials. Since brides were always required to have less schooling than their husbands, parents had tended before 1970 to keep their daughters from attending school at all or for not more than a few years before marriage. This practice contrasted with that of another high caste of Newars, the Shresthas, who as Hindus traditionally employed by the King of Nepal took advantage of Western-type educational opportunities for their sons and - as soon as girls' schools opened in the 1940s-permitted their daughters to attend them. During the 1970s and 1980s, when the women in our sample were children, all caste groups increasingly sent their children, female as well as male, to school. Nevertheless, there was more schooling among Shrestha mothers, less among the Vajrajcaryas and Shakyas, and still less among those from the middlerank farming Maharjan caste. Mothers reported that their length of school attendance depended on their parents' caste-based perception of whether more schooling would hurt their chances of a good marriage at that time, plus situational factors such as the need for them to take care of younger siblings, rather than their own preferences or performance in school (S. LeVine, n.d.).

The rural sample was drawn from the village area of Godavari, where our previous study had been conducted in 1989-1990 (Joshi, 1994). Roughly 8 miles south of Patan, Godavari is a fertile agricultural area set against the low-lying Mahabarat mountains bordering the southern edge of the Kathmandu Valley. Like the urban research site, Godavari is inhabited by several ethnic and caste groups, but we sampled only the high-caste Nepalispeaking Parbatiya Hindus (Brahmins and Chetris) because they are the only ones among whom women have attended school. These high-caste Hindus own and farm the fertile land on the valley floor. They are smallscale farmers who live in dispersed homesteads, with the houses of each patriarchal joint family adjoining its own cultivated fields. The fields are irrigated and produce three crops - wheat, rice and mustard seed - each year, but many of the men commute to town for employment while their wives tend the crops. Meanwhile, shops and factories spread along the paved road nearby, bringing the city closer to Godavari each year. The people we studied were becoming peri-urban cultivators, though still with a rural life style. Like the populations of northern India to whom they are related in language, religion and other aspects of culture, the BrahminChetris of Godavari practice a form of patrilocal residence at marriage in which brides of the same caste from other communities move to the homes of their husbands' fathers (Bennett, 1983). Thus the married women of Godavari did not grow up there, and many come from rural areas distant from the city, where schools were still rare or nonexistent when they were children. Only $43 \%$ of the rural sample mothers had attended school, and the distribution of school attendance among them reflects whether or not there was a 
school in their village, parental apprehensions about their marriage chances (as in Patan), and (also as in Patan) the need for their labor in child care (S. LeVine, s.d.). By drawing our rural and urban samples from high-caste and (in the case of Patan) middle-caste populations, we controlled a major source of variance in women's school entry and attrition found in the 1991 survey by Stash and Hannum (2001), viz. caste. It nonetheless proved necessary to control for caste in Patan in the analyses presented below.

In Patan as in Godavari, a majority of married women live in patrilineal extended ("joint") households (see Table 4), with their parents-in-law, husbands' brothers, and the brothers' wives and children. Their obligations to work and carry out rituals are specified by institutionalized norms and enforced by the older generation. Tasks are generally shared among the women of the house, but the pressures on young wives in Godavari differ from those of Patan. In Godavari, where the wives come from outside the community, they tend to be dominated by their husbands' mothers, who are particularly concerned that the young women work hard in the fields and the home. If a mother-in-law makes unreasonable demands, the wife has no one to turn to but her husband. In Patan, however, wives often come from nearby families with whom they have daily contact after marriage. This social context and the smaller work burden for urban women operate to protect Newar mothers from the kind of domination and restrictions that can affect their Parbatiya counterparts in Godavari.

\section{The samples}

In Patan and Godavari, samples were drawn of mothers who had children in kindergarten (lower or upper) or class 1 of primary school, from a cluster of households in the center of a designated neighborhood in each community, in order to study the intergenerational transmission of literacy and language skills from mothers to their children (to be reported in a subsequent article). The children ranged from 4 to 8 years of age. Given our focus on school-based literacy, we deliberately over-sampled women who had attended school in order to achieve a relatively equal distribution across levels of school attainment. Interviewers canvassed the neighborhood, from the center outward, for women with the designated characteristics until a sample of at least 80 was found and selected.

Table 3 presents the percentage of mothers from our urban and rural samples combined in each level of school attainment compared with a sub-sample of evermarried women who reported a birth in the last 5 years, from the 1991 Lalitpur probability sample of the Nepal Fertility, Family Planning and Health Status Survey. In
Table 3

Percentage of mothers at each level of schooling in two samples from Lalitpur District, Nepal

\begin{tabular}{lcl}
\hline Schooling level & $\begin{array}{l}1991 \text { survey } \\
(n=117)^{\mathrm{a}}\end{array}$ & $\begin{array}{l}1997 \text { study } \\
(n=167)^{\mathrm{b}}\end{array}$ \\
\hline 0 (no schooling) & $67.5(79)$ & $35.3(59)$ \\
1 (1-4 years) & $7.7(9)$ & $16.8(28)$ \\
2 (5-9 years) & $14.5(17)$ & $18.6(31)$ \\
3 (10+ years) & $10.3(12)$ & $29.3(49)$ \\
\hline
\end{tabular}

Note: $n$ 's for each schooling level are presented in parentheses.

${ }^{\text {a }}$ From the probability sample of Lalitpur District selected for the 1991 Nepal Fertility, Family Planning and Health Status Survey. Total sample size $=291$ ever-married women aged 15 49 years, sub-sample $=117$ women who reported a birth in previous 5 years.

${ }^{\mathrm{b}}$ From the community-level samples of Patan and Godavari selected by the authors for the field study conducted from 1996 to 1998 .

the 1991 survey, more than two-thirds of the women had not been to school at all; in our combined sample, only $35.3 \%$ were in this category; about the same proportion had attended school for up to 9 years, and the rest $(29.3 \%)$ had 10 or more years of schooling. It is also worth noting that in the 1991 probability sample only $7.7 \%$ had attended school for $1-4$ years, indicating a strong tendency of girls who begin primary school to complete the full 5 years, and making it difficult to find mothers in this category of school attainment, particularly in our rural site.

Table $4 \mathrm{a}$ and $\mathrm{b}$ present demographic and related characteristics of our urban sample in Patan and rural sample in Godavari, respectively. As might be expected in a country where socioeconomic change is recent, the two samples are much more similar in schooling levels and current and desired fertility than is often found in urban-rural comparisons. The only striking difference is that $12.8 \%$ of the urban women's mothers had been to school, whereas only $3.7 \%$ of the rural women's mothers had. Patan women had slightly fewer living children, as might be expected, but expressed the desire for about the same number of children as their rural counterparts. Their average numbers of desired children, 2.2-2.3, were slightly under the averages for urban ever-married women of the same age in Nepal as a whole (25-29 years old, $2.4 ; 30-34,2.5$ in the 1996 NFHS), which is consonant with their location in the Kathmandu metropolitan area.

Maternal schooling is related to fertility and health behavior in these samples. The partial correlation of maternal schooling with number of living children in the two samples combined, controlling for maternal age, is -0.37 ( $p<0.001)$; controlling for age, current SES and childhood SES, the partial correlation is -0.23 
Table 4

Demographic characteristics of: (a) women in Patan (urban Nepal sample) $(n=86)$ and Godavari (rural Nepal sample) $(n=81)$

\begin{tabular}{|c|c|c|}
\hline & Mean (SD) & Range \\
\hline \multicolumn{3}{|l|}{$\begin{array}{l}\text { (a) Women in Patan (urban Nepal } \\
\text { sample) }(n=86)\end{array}$} \\
\hline Woman's age & $30.8(4.9)$ & $22-49$ \\
\hline Woman's schooling (years) & $6.2(5.0)$ & $0-16$ \\
\hline Husband's schooling (years) & $9.0(4.5)$ & $0-16$ \\
\hline Children living (number) & $2.4(1.0)$ & $1-7$ \\
\hline Desired number of children & $2.3(0.7)$ & $1-5$ \\
\hline Women living in joint households & $60.5 \%$ & \\
\hline $\begin{array}{l}\text { Woman's mother had formal } \\
\text { schooling }\end{array}$ & $12.8 \%$ & \\
\hline Woman's mother could read & $18.6 \%$ & \\
\hline $\begin{array}{l}\text { Woman's father had formal } \\
\text { schooling }\end{array}$ & $54.8 \%$ & \\
\hline Woman's father could read & $73.3 \%$ & \\
\hline \multicolumn{3}{|l|}{$\begin{array}{l}\text { (b) Women in Godavari (rural } \\
\text { Nepal sample) }(n=81)\end{array}$} \\
\hline Woman's age & $28(3.9)$ & $20-38$ \\
\hline Woman's schooling (years) & $4.1(4.7)$ & $0-12$ \\
\hline Husband's schooling (years) & $9.9(3.2)$ & $1-16$ \\
\hline Children living (number) & $2.7(0.9)$ & $1-7$ \\
\hline Desired number of children & $2.2(0.7)$ & $1-5$ \\
\hline Women living in joint households & $51.9 \%$ & \\
\hline $\begin{array}{l}\text { Woman's mother had formal } \\
\text { schooling }\end{array}$ & $3.7 \%$ & \\
\hline Woman's mother could read & $14.6 \%$ & \\
\hline $\begin{array}{l}\text { Woman's father had formal } \\
\text { schooling }\end{array}$ & $55 \%$ & \\
\hline Woman's father could read & $84.1 \%$ & \\
\hline
\end{tabular}

$(p<0.01)$, and it is stronger in Patan $(-0.29, p<0.01)$ than in Godavari $(-0.21, p<0.10)$. (The desired number of children shows no significant relationship with schooling when these controls are introduced.) The partial correlation of schooling with the earliness of the mother's prenatal care in her last pregnancy, controlling for age and SES, is $0.26(p<0.001)$. Thus the samples showed the connections between maternal schooling and reproductive outcomes (or in the case of infant mortality, a health practice related to the outcome) necessary for a study of pathways through which schooling might influence vital facets of maternal behavior.

\section{Methods}

All 167 mothers were interviewed and their literacy and language skills were assessed. The maternal interview covered the woman's socioeconomic and educational background, the schooling of her parents and siblings, the current socioeconomic conditions in which she was raising her children, her reproductive and health behavior, her knowledge of child development, and her attitudes toward her own children. The assessment of maternal literacy and language skills included reading comprehension, academic language proficiency (noun definitions), comprehension of health messages in both print and broadcast media, comprehension of instructions on a packet of oral rehydration salts, and the ability to provide a health narrative in an interview situation resembling that used in clinics. The literacy and

Table 5

Descriptive statistics for maternal literacy and health-related measures in urban and rural Lalitpur District, Nepal

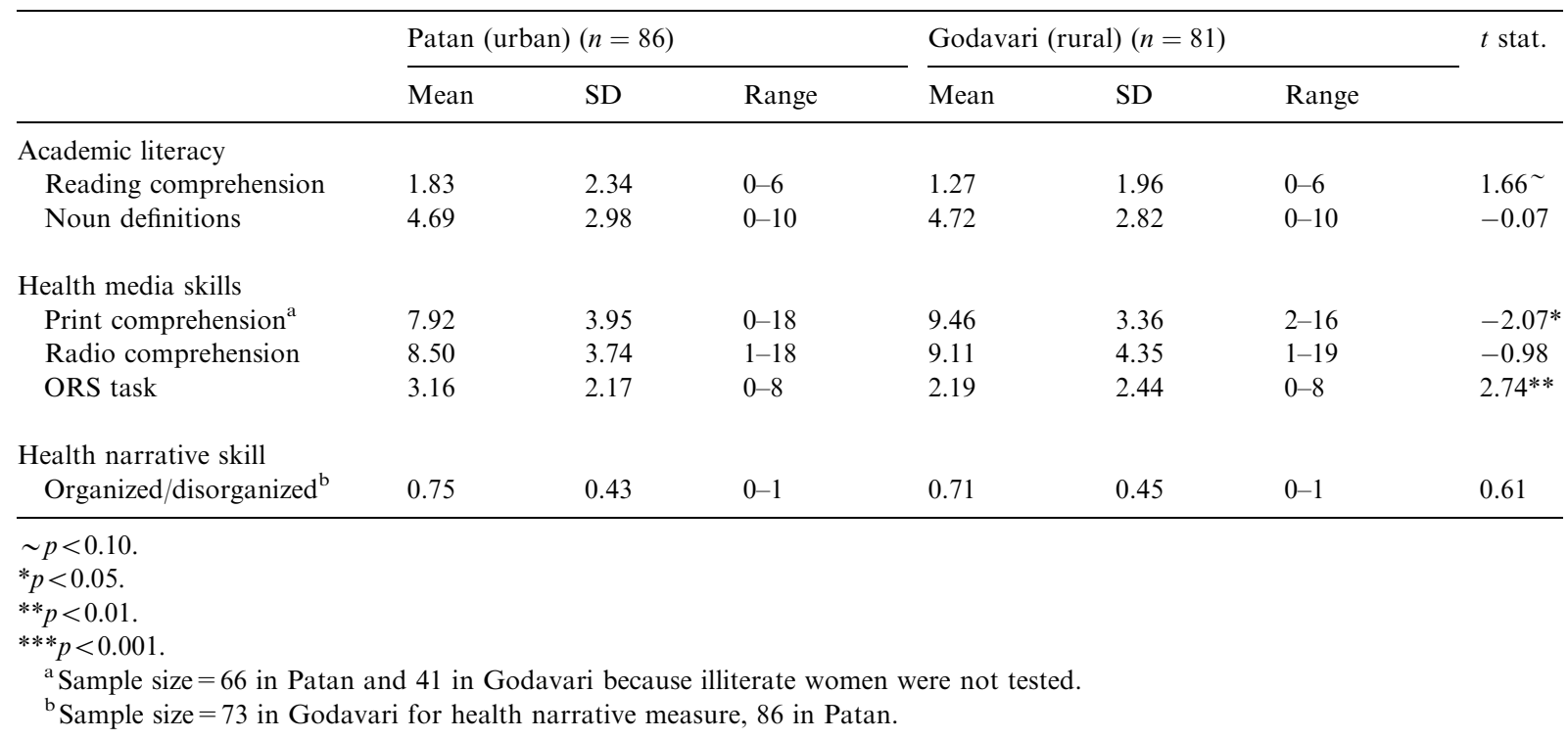


language assessment tasks are described in detail in Appendix A.

\section{Findings and interpretations}

In this section we present the results of our studies in Patan and Godavari, evaluating direct literacy assessment as a method and exploring the relationships posited by the theoretical model in Fig. 1. Table 5 shows the means, standard deviations and ranges for the six literacy and health measures included in this analysis. (Some of the functional literacy measures were excluded because they were not administered to women with six or more years of schooling, thus reducing sample size.) The table shows the Patan and Godavari distributions separately and the results of $t$ tests for differences between them. Only two variables showed significant differences, with Godavari higher on one (Print Comprehension) and Patan higher on another (ORS). Thus, the overall distributions are similar in the rural and urban samples.

\section{Comparison of self-reported reading ability with direct assessment}

Self-reports of their reading ability were elicited from the sample mothers in an early interview when they did not know they would be tested some months later. When asked if they could read, $23 \%$ of the mothers said "no", $25 \%$ said "a little", and $52 \%$ said "yes". Of those who said "yes", $27.6 \%$ proved to have an actual reading level of 0 on the reading test. This contrasts with the parallel figure of $17.1 \%$ from the large-scale Bangladesh literacy study (Greaney, Khandker, \& Alam, 1999), in which respondents apparently did know they would be tested after their self-report and might have been reluctant to make a claim that would soon be exposed as false. The conditions for eliciting self-reports in Nepal more closely approximated that of a survey or census interview in which self-report is the only measure of literacy, and the finding suggests a problem of inflated claims, with more than a quarter of those reporting the ability to read not able to do so on a test. Literacy testing reduced the proportion of Nepalese sample women who might be reported as "literate" in this basic sense from $52 \%$ to $38 \%$ - a difference that could well be interpreted as significant in policy discussions. If this finding is replicated, it represents a serious validity problem in self-report as an approach to literacy in population studies. The need for direct literacy assessment is even more evident in attempting to capture literacy skills other than basic reading ability, e.g., the noun definition or health media comprehension skills examined in this study, which on their face cannot be accurately selfassessed.

\section{Rural Godavari}
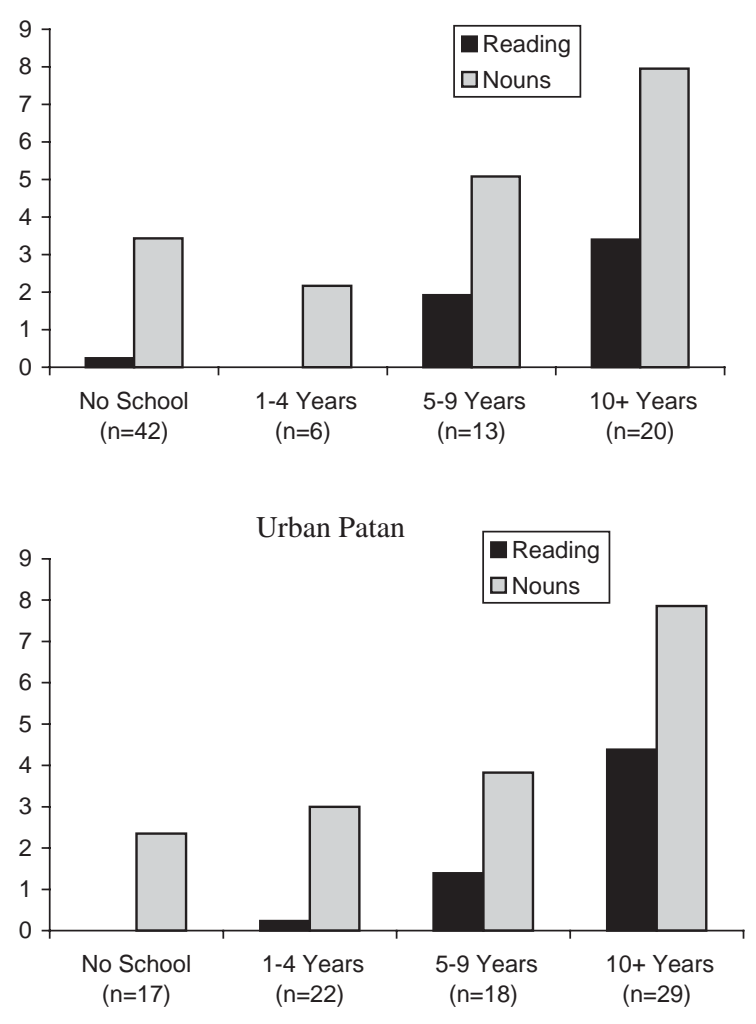

Fig. 2. Mean maternal reading comprehension and noun definition test scores by level of schooling in rural (top) and urban (bottom) Lalitpur District Nepal.

\section{Retention of skills acquired in school}

The findings concerning retention of academic literacy skills are displayed in Fig. 2 and Tables 6 and 7. Fig. 2 shows that, when four levels of school attainment are used, there is a clear association of maternal schooling with higher scores on reading comprehension and academic language (noun definitions) in both Godavari and Patan. In Patan the women with 10 or more years of schooling had an average reading comprehension score of 4.38 on a scale of $0-6$, as compared with an average score of 0.23 for women with 1-4 years of school, suggesting that the women with the highest level of schooling were comprehending text written on a seventh-grade level by Nepal school standards. Reading comprehension scores are slightly lower on average in Godavari, but the superior reading comprehension of the women with more schooling is still evident. The same can be said for scores on the noun definition task, a test of academic language skill (Snow, 1990): In Patan the average score for women with 10 or more years of schooling was 7.86 out of a possible score of 10 , as 
Table 6

Simple correlations (Pearson's $r$ ) of mother's schooling with literacy, health and socioeconomic variables in urban and rural Lalitpur District, Nepal

\begin{tabular}{|c|c|c|}
\hline & $\begin{array}{l}\text { Patan (urban) } \\
(n=86)\end{array}$ & $\begin{array}{l}\text { Godavari (rural) } \\
(n=81)\end{array}$ \\
\hline \multicolumn{3}{|l|}{ Academic literacy } \\
\hline Reading comprehension & $0.79 * * *$ & $0.72 * * *$ \\
\hline Noun definitions & $0.77 * * *$ & $0.66^{* * *}$ \\
\hline \multicolumn{3}{|l|}{ Health media skills } \\
\hline Print comprehension ${ }^{\mathrm{a}}$ & $0.64 * * *$ & $0.46^{* *}$ \\
\hline Radio comprehension & $0.63 * * *$ & $0.56^{* * *}$ \\
\hline ORS task & $0.67 * * *$ & $0.72 * * *$ \\
\hline \multicolumn{3}{|l|}{ Health narrative skill } \\
\hline Organized/disorganized ${ }^{\mathrm{b}}$ & $0.41 * * *$ & $0.26^{*}$ \\
\hline \multicolumn{3}{|l|}{ Socioeconomic variables } \\
\hline Age & 0.10 & $-.41 * * *$ \\
\hline Husband's schooling & $0.68 * * *$ & $0.60 * * *$ \\
\hline Current SES & $0.68 * * *$ & $0.44 * * *$ \\
\hline Childhood SES & $0.37 * * *$ & $0.36^{* *}$ \\
\hline Caste & $0.48 * * *$ & NA \\
\hline
\end{tabular}

$* p<0.05$.

$*^{* *} p<0.01$.

$* * * p<0.001$

NA, not applicable for the site.

${ }^{\mathrm{a}}$ Sample size $=66$ in Patan and 41 in Godavari because illiterate women were not tested.

${ }^{\mathrm{b}}$ Sample size $=73$ in Godavari for health narrative measure, 86 in Patan.

compared with 2.4 for women with no schooling at all and 3.0 for women with only 1-4 years of school. In Godavari women in the highest category averaged 7.95 on noun definitions, compared with 3.5 for unschooled women and 5.3 for those with 5-9 years of school.

In Godavari, the women with incomplete primary school (of whom there were only six) performed worse on both tests than those with no schooling. This may be the result of the unschooled rural women's participation in adult literacy classes (hence their scoring higher than their counterparts in urban Patan), but the poor performance of those with incomplete primary schooling is not easily explained, given their small numbers.

Table 6 shows the estimated simple correlations of maternal schooling as a continuous variable with the academic literacy skills and nine other variables. Reading Comprehension and Noun Definitions are highly correlated with schooling in both samples, with correlations ranging from 0.66 to $0.79(p<0.001)$, but maternal schooling is also highly correlated with the socioeconomic variables at the bottom of the table, so a multivariate analysis is called for.
Some of the functional literacy tasks not shown in Tables 5 or 6 are not as closely related to maternal schooling. For example, the labels and signs task showed simple correlations of 0.24 (n.s.) in Patan and $0.29(p<0.05)$ in Godavari, indicating that - as might be expected - such knowledge is not as dependent on school learning. (This task was given only to women with less than 6 years of school, so the sample size and range were reduced.) Oral arithmetic, however, is correlated $0.47(p<0.001)$ in Patan and $0.34(p<0.01)$ in Godavari. For the regression modeling we chose only jeevan jal, as it represents a functional literacy skill in a critical context of child health; all women were given this task.

Table 7 shows the regression of the two literacy variables on a mother's schooling and the socioeconomic variables. Maternal schooling is a significant predictor of Noun Definitions and Reading Comprehension in all four models, with the socioeconomic factors controlled, and the models account for an estimated 45$71 \%$ of the variation in the literacy outcomes. (The caste variables in Patan and Current SES in Godavari are the only other significant predictors.)

This pattern of results, replicated in the urban and rural samples, indicates that the mothers have retained literacy skills they acquired in school. It does not mean that their reading and academic language skills are as good as they were when they left school or that they reach an acceptable standard of minimum performance, but only that their differential performances are predictable from their school attainment. Had those who progressed further in school not performed better, then retention would not be indicated. This is as strong a body of evidence of literacy retention as could have been obtained with these particular tests and without longitudinal data. It is consistent with findings from the longitudinal studies of literacy retention conducted by Wagner (1993) in Morocco and Gorman and Pollitt (1997) in highland Guatemala.

\section{Influence of literacy on health media skills}

Do the literacy skills influence the mothers' ability to understand health messages in various media? Tables 8 and 9 show the results concerning that question. To conduct these analyses we constructed a Literacy Composite variable, comprised of the Reading Comprehension and Noun Definitions scores, through principal components analysis, and merged the rural and urban samples to augment sample size. We regressed comprehension scores for both radio and print health messages on schooling and socioeconomic controls (this time including an urban-rural dummy variable), in a First Model without the Literacy Composite and a Final Model with it. Table 8 shows that for radio and print messages, the addition of the Literacy Composite, which 
Table 7

Regression models predicting literacy skills (formal noun definitions, reading level) on the basis of maternal schooling controlling for SES in urban and rural Lalitpur District Nepal ${ }^{\mathrm{a}}$

\begin{tabular}{|c|c|c|c|c|}
\hline \multirow[t]{3}{*}{ Predictors } & \multicolumn{4}{|l|}{$\beta$ coefficient (SE) } \\
\hline & \multicolumn{2}{|c|}{ Academic language (noun definitions) } & \multicolumn{2}{|l|}{ Reading level } \\
\hline & Patan (urban) $(n=86)$ & Godavari (rural) $(n=81)$ & Patan (urban) $(n=86)$ & Godavari (rural) $(n=81)$ \\
\hline Intercept & $3.87 *(1.20)$ & $3.42(2.33)$ & $1.45(1.24)$ & $-1.17(1.40)$ \\
\hline Maternal schooling & $0.42 * * *(0.07)$ & $0.37 * * *(0.07)$ & $0.23 * *(0.05)$ & $0.24 * * *(0.05)$ \\
\hline Childhood SES & $0.45(0.36)$ & $0.03(0.49)$ & $0.24(0.26)$ & $0.12(0.30)$ \\
\hline Age & $-0.03(0.05)$ & $-0.02(0.07)$ & $-0.05(0.03)$ & $0.02(0.04)$ \\
\hline Current SES & $-0.13(0.23)$ & $0.25(0.28)$ & $0.25(0.17)$ & $0.43 *(0.17)$ \\
\hline Husband's Schooling & $0.01(0.07)$ & $0.001(0.09)$ & $0.08(0.05)$ & $0.05(0.06)$ \\
\hline Caste $1^{\mathrm{b}}$ & -1.14 & NA & $-1.17^{*}$ & NA \\
\hline Maharjan & $-(0.70)$ & & $(0.50)$ & \\
\hline Caste 2 & $-1.80 * *$ & NA & $-1.53 * *$ & NA \\
\hline Sakya & $(0.66)$ & & $(0.48)$ & \\
\hline Caste 3 Vajracarya/Brahmin & $-1.42 *(0.71)$ & NA & $-0.05(0.03)$ & NA \\
\hline$R^{2}$ stat. (error d.f.) & $0.6481(77)$ & $0.4469(75)$ & $0.7061(77)$ & $0.5602(75)$ \\
\hline
\end{tabular}

$* p<0.05$.

$*^{* *} p<0.01$.

$* * * p<0.001$

NA, not applicable for the site.

${ }^{a}$ For all regression analyses presented, background variables, despite statistical non-significance, are retained to show the controlled effects of maternal years of schooling on each outcome. In addition, interaction effects models were fit, but no interaction effects were found.

${ }^{\mathrm{b}}$ Omitted caste $=$ Shresta/Chetri. The negative parameter estimates for the caste variables indicates academic language and reading levels lower than for the Shresta/Chetri caste (the highest caste) not included in the models, controlling for the other variables in the model.

is a highly significant predictor, attenuates the effect of maternal schooling (from highly significant in the First Model to non-significance in the case of radio and borderline significance in the case of print) and raises the proportion of variation accounted for, from $40 \%$ to $52 \%$ in the case of radio and from $39 \%$ to $52 \%$ in the case of print. The Literacy Composite is the major predictor of both health comprehension outcomes and seems to be the pathway through which schooling exerts its influence (although Current SES and Age remain significant predictors for radio comprehension). This is particularly interesting in the case of radio messages, which are intended to reach those who cannot read but are apparently better understood by more literate women.

Table 9 shows the analysis of findings from the task of describing the preparation of ORS (in Nepali, jeevan jal) after being shown the packet with a label; the task, intended to reach low-literacy mothers, involves pictures as well as text and has a numerical component, so that it differs from a school reading comprehension task. Patan and Godavari were analyzed separately. In both sites the addition of the Literacy Composite increases the amount of variation accounted for and attenuates
Maternal Schooling, though not to non-significance, and the Literacy Composite itself is only of borderline significance as a predictor in Patan. This is a task in which the influence of schooling on the outcome is only partly mediated by literacy, due to its graphical and numerical components.

\section{Influence of literacy on health narrative skill}

Do a mother's academic literacy skills influence her ability to tell a coherent story about an illness-her own or her child's - to an interviewer? The narratives elicited by our interviewers were coded dichotomously as organized or disorganized by Nepalese coders; $74 \%$ were coded as organized. Table 10 shows a logistic regression analysis. In the first model, narrative organization is regressed on Maternal Schooling and socioeconomic variables, and Schooling is the only significant predictor. When the Literacy Composite is introduced in the final model, Schooling is attenuated to insignificance, Literacy is the only significant predictor, and the amount of variation accounted for is increased from $14.8 \%$ to $18 \%$. This suggests that the effect of schooling on the ability to tell an organized health narrative, 
Table 8

Regression models predicting comprehension of radio and printed health messages on the basis of maternal schooling and socioeconomic controls, with and without literacy skills, Lalitpur District, Nepal

\begin{tabular}{|c|c|c|c|c|}
\hline \multirow[t]{3}{*}{ Predictors } & \multicolumn{4}{|c|}{$\beta$ coefficient (SE) } \\
\hline & \multicolumn{2}{|c|}{ Auditory radio messages $(n=167)$} & \multicolumn{2}{|c|}{ Visual print messages $(n=107)$} \\
\hline & First Model & Final Model & First Model & Final Model $^{\mathrm{a}}$ \\
\hline Intercept & $0.12(1.03)$ & $1.56(0.95)$ & $-0.63(1.34)$ & $0.87(1.23)$ \\
\hline Maternal Schooling & $0.26 * * *(0.04)$ & $0.06(0.05)$ & $0.33 * * *(0.06)$ & $0.13^{\sim}(0.07)$ \\
\hline Childhood SES & $0.58 *(0.28)$ & $0.4^{\sim}(0.25)$ & $0.61^{\sim}(0.35)$ & $0.46(0.32)$ \\
\hline Age & $-0.07 *(0.03)$ & $-0.07 *(0.03)$ & $-0.06(0.04)$ & $-0.05(0.04)$ \\
\hline Current SES & $-0.32^{\sim}(0.16)$ & $-0.44 * *(0.15)$ & $-0.16(0.20)$ & $-0.27(0.18)$ \\
\hline Husband's Schooling & $0.08^{\sim}(0.05)$ & $0.05(0.05)$ & $-0.02(0.07)$ & $-0.07(0.07)$ \\
\hline Urban/Rural Dummy & $-0.28(0.37)$ & $0.04(0.33)$ & $-0.67(0.52)$ & $-0.41(0.47)$ \\
\hline Literacy Composite & & $1.11 * * *(0.18)$ & & $1.08 * * *(0.21)$ \\
\hline$R$ stat. (error d.f.) & $0.4039(160)$ & $0.5230(159)$ & $0.3908(100)$ & $0.5175(97)$ \\
\hline
\end{tabular}

$\sim p<0.10$.

${ }^{*} p<0.05$.

$* * p<0.01$.

$* * * p<0.001$.

a An alternate 'final model' was fit testing two-way interactions between urban/rural residence and other predictors. The interactions with current and childhood SES proved significant. We chose not to present that model here in the interest of clarity and because the SES variables are controls and are not of primary importance in our analyses.

Table 9

Regression model predicting the number of idea units from jeevan jal on the basis of maternal schooling and literacy skills controlling for age and SES for Patan and Godavari separately

\begin{tabular}{|c|c|c|c|c|}
\hline \multirow[t]{4}{*}{ Predictors } & \multicolumn{4}{|l|}{$\beta$ coefficient (SE) } \\
\hline & \multicolumn{4}{|l|}{ ORS task } \\
\hline & \multicolumn{2}{|c|}{ Patan (urban) $(n=86)$} & \multicolumn{2}{|c|}{ Godavari (rural) $(n=81)$} \\
\hline & First model & Final model & First model & Final model \\
\hline Intercept & $7.17 * * *(1.38)$ & $7.28 * * *(1.36)$ & $1.11(1.77)$ & $2.24(1.64)$ \\
\hline Maternal Schooling & $0.27 * * *(0.06)$ & $0.19 * *(0.07)$ & $0.31 * * *(0.06)$ & $0.15^{*}(0.07)$ \\
\hline Age & $-0.12 * *(0.04)$ & $-0.11 * *(0.04)$ & $-0.05(0.05)$ & $-0.05(0.05)$ \\
\hline Childhood SES & $-0.01(0.29)$ & $-0.09(0.29)$ & $0.14(0.39)$ & $0.10(0.35)$ \\
\hline Current SES & $-0.07(0.19)$ & $-0.09(0.18)$ & $-0.06(0.22)$ & $-0.25(0.21)$ \\
\hline Husband's schooling & $-0.06(0.05)$ & $-0.07(0.05)$ & $0.11(0.07)$ & $0.10(0.07)$ \\
\hline Caste $1,{ }^{\text {a }}$ Maharjan & $-2.22 * * *(0.56)$ & $-1.93 * *(0.57)$ & NA & NA \\
\hline Caste 2, Sakya & $-1.17 *(0.53)$ & $-0.75(0.57)$ & NA & NA \\
\hline Caste 3, Vajracarya/Brahmin & $-0.81(0.56)$ & $-0.55(0.57)$ & NA & NA \\
\hline Literacy composite & & $0.44^{\sim}(0.24)$ & & $0.94 * * *(0.24)$ \\
\hline$R^{2}$ stat. (error d.f.) & $0.5740(77)$ & $0.5931(76)$ & $0.5420(75)$ & $0.6224(74)$ \\
\hline
\end{tabular}

$\sim p<0.10$.

${ }^{*} p<0.05$.

$* * p<0.01$.

$* * * p<0.001$.

NA, not applicable for this site.

${ }^{\text {a } O m i t t e d ~ c a s t e ~}=$ Shresta $/$ Chetri. A negative parameter estimate for any caste variable indicates lower scores on the ORS task than for the Shresta/Chetri caste (the highest caste) not included in the models, controlling for the other variables in the model. 
most parents of child-bearing women of the 1990s had not been to school themselves (S. LeVine, n.d.; Stash \& Hannum, 2001). In Patan, where the sample covered a socially stratified neighborhood, it was actually some of the highest status Newar Buddhist castes that had been among the lowest in school attainment (for women as well as men) because of the persistence of traditional male occupations into the decades when the sample women were eligible for marriage. Meanwhile, the rural Godavari mothers in our sample, all high-caste Hindus with locally exogamous marriage, tended to come from distant villages that did not have schools 20 years earlier when they were of an age to enter school. In cases where there had been a school and the girl had attended, she was withdrawn for an early marriage regardless of her academic performance - a common action at that time, before the average age at marriage began to increase. Here again, high-caste status had been associated with truncated schooling for girls (a pattern mentioned by Stash \& Hannum, 2001, pp. 374-377).

None of the forces determining how far sample mothers progressed in school fits the expectation of selectivity by ability, wealth or social standing. From that point of view, the sample was especially suitable for studying the effects of schooling independently of prior advantages. School attendance was not randomly assigned, as it would be in an experiment, but its distribution among the women studied was due in large measure to heterogeneous family circumstances that Nepalese parents had permitted to prevent or terminate their daughters' schooling rather than to the dominant drag of social and intellectual advantage. This strengthens our confidence that the findings from Nepal reflect the impact of schooling and literacy rather than the factors often associated with them in other contexts.

Taking the findings from Nepal together with our previous studies that directly assessed literacy skills in Mexico, Zambia and Venezuela and with the larger surveys in Morocco, South Africa and Guatemala mentioned above, it is evident that literacy can be part of the pathway from female schooling to health behavior and reproductive change in diverse parts of the developing world. By focusing on the connections among school attainment, literacy skills and health skills (Boxes 1-3 in Fig. 1), this study has helped illuminate a "black box" left by previous research. More illumination is needed on the links of schooling to utilization of public health and family planning services, but these findings point clearly to the hypothesis that learning to read at increasingly higher levels of comprehension, and learning to communicate orally in the academic language that includes abstract nouns, can facilitate effective use of services.

Schooling can of course provide women with credentials for higher status, liberation from traditional family constraints, and modern ideas and attitudes, but evidence is accumulating that school learning, even in low-quality schools, also leaves permanent marks on a woman's repertoire of skills, particularly literacy skills. The Gorman and Pollitt (1997) literacy assessment of 1084 rural Guatemalans aged 11-26 years who had been studied as young children in the INCAP nutrition project is a case in point. Those who had attended school for 3 or 4 years tested as literate, despite having parents with little or no schooling and going to schools that were "not optimal" in impoverished villages of eastern Guatemala. Thus small doses of conventional schooling, even when indifferently delivered, can have a long-term impact on literacy. Our Nepal findings show that larger doses, extended to the end of primary schooling and beyond, increase the impact substantially. Literacy operates in collaboration with other cognitive, motivational and situational factors to affect health behavior, but as readily measurable individual characteristics, directly assessed literacy and language skills may prove particularly useful in tracking relationships between schooling and health communications.

\section{Acknowledgements}

This research was funded by the William T. Grant Foundation (Grant nos. 96175896 and 1758.01). The field study was conducted by Sarah LeVine with the assistance of Deepa Pokharel, Jyoti Tiwari and Saruna Amatya, all of whom have Master's degrees and are native speakers of Nepali (Pokharel and Tiwari) or Newari (Amatya). We are indebted to Sudhindra Sharma and Deepak Gyawali of Interdisciplinary Analysts and Sumon Tuladhar, then of the Centre for Educational Research in Development (CERID) of Tribhuvan University, for their support in Kathmandu. Beatrice Schnell designed and pretested the literacy instruments. Binayak Dungana entered the data. Alina Martinez organized the data processing and conducted initial data analysis; Meredith Rowe conducted the final analyses. Seeta Pai carried out preliminary analyses of the Lalitpur District data from the 1991 NFFPHS. Emily Dexter's advice on data analysis and presentation was invaluable.

\section{Appendix A}

Reading comprehension: This task, based on Chall's (1996) assessment method, consisted of six healthrelated texts graded by difficulty of comprehension according to school grade levels 1, 3, 5, 7, 9 and the first post-secondary year. The testing was done in Nepali because it is the school language for all and because most Newars cannot read the script in which the Newari 
language is written. Each woman was asked to read the texts and asked questions about their contents. Her score was the grade level at which she was able to answer $50 \%$ of the questions. Mothers who were not able to answer $50 \%$ at grade level 1 received a score of 0 . The scores were converted into a continuous scale of $0-6$. Thus, the mean scores for reading shown in Fig. 2 are based on this scale and do not represent the actual grade or class levels in school of the mothers' performance.

Noun definitions: This task was based on the method and rationale of Snow (1990) and had been used in our own previous field studies. Each mother was asked to define 10 nouns for common objects, such as "knife", "thief" and "dog," with the question, "What is a _-_?" Their responses were scored for the presence or absence of superordinate category membership ("a dog is an animal..."), and the scores shown in Fig. 2 are the mean number of objects for which a superordinate term like "animal" was given; this is an indicator of what Snow calls decontextualized language use. Decontextualization in this sense refers to the ability to communicate meaning through words alone to someone who does not share the same context in background knowledge or current experience; it does not mean that any verbal communication is entirely free of context. The ability to use the less contextual, more abstract and more explicit language taught in schools to define a noun is our measure of academic language proficiency.

Comprehension of radio health messages: All mothers were played a tape recording of three health messages that were broadcast regularly on the radio in Nepal. The first message emphasized the importance of using oral rehydration salts when a person, especially a child, has diarrhea; the second was about family planning and mentioned depo provera as an example of an effective contraceptive method; and the third explained how vaccinations can save children's lives. The content of each of these messages was divided into idea units. Mothers were told to listen carefully to each message and to tell the examiner everything they could remember. Responses were coded for idea units mentioned, the total number of which constituted a score. The maximum score was 29 , with nine idea units for ORS, eight for family planning and 12 for vaccinations.

Comprehension of printed health messages: Mothers who had attended school (66 in Patan and 41 in Godavari) were presented with three additional radio messages but in written form, concerning the importance of vaccinating dogs against rabies, the importance of female literacy and the benefits of teaching children to defecate in a toilet (environment will look cleaner, less danger of spreading germs). Mothers were given each print message and asked to take as much time as they needed to read it. Then they were asked to tell the examiner everything they could remember about each message they had read. Their responses were coded for idea units. The maximum total score mothers could obtain was 27 , with eight for rabies, five for female literacy and 14 for defecating in the toilet.

Functional literacy: These tasks were designed to assess literacy skills usable in specific contexts of Nepalese women's lives: (a) labels and signs (environmental print), (b) reading time, (c) oral arithmetic (functional numeracy) and (d) document literacy.

Labels and signs: Mothers were shown seven different pictures depicting food labels (milk, salt) and street signs (danger, red cross, go slow, bus stop, family planning) they encountered on a daily basis. First they were asked to tell the interviewer what they thought the sign or label meant (identification). Then they were asked whether they had ever seen such a label or sign before and if they could remember where. (Locations such as "at the market", "close to a school," or "at the hospital.")

Reading time: Mothers were shown pictures of clocks showing different times and asked to identify the time shown on each one.

Oral arithmetic or functional numeracy: Mothers were read four arithmetic word problems and asked to come up with the correct answer. All word problems were adapted to situations Nepali women encounter on a daily basis, such as estimating the number of rotis she had to make for a family of two adults and two children, estimating bus fare, estimating preparation time for a wedding. (Exact words are available on request.)

Document literacy: These tasks were based on four documents that women in Nepal are familiar with, regardless of schooling: a jeevan jal (ORS) packet, a doctor's prescription with words and drawings of the dosage the child has to take (commonly inscribed by doctors), a child immunization card and a school registration form. Since the analysis presented below is limited to the jeevan jal task, we describe only that task: Mothers were shown an enlarged version of the packet of ORSs that is used in Nepal, which provides the instructions of how to prepare jeevan jal using both pictures and print. Then they were asked to read/look at the instructions and describe what they would do in the case of a 1-year-old child with severe diarrhea. Interviewers were asked not to provide any help to the mothers, not even the illiterate mothers. Responses were coded on the basis of nine idea units included in the five steps of preparation shown on the jeevan jal packet. These were as follows:

Step 1: Wash your hands with SOAP and WATER (two idea units).

Step 2: Pour SIX glasses of DRINKING water into a CLEAN vessel (three idea units).

Step 3: Pour the ENTIRE content of the packet into the water and STIR properly (two idea units).

Step 4: Give the child some of this water EVERY TIME he has diarrhea (one idea unit). 
Step 5: Give the child mother's milk, food and other liquids, MORE than he or she usually gets (one idea unit).

Mothers were also asked if they had ever used a jeevan jal packet, and if they had, whether someone had helped them interpret the instructions. Responses to these two questions were classified into one of three categories: (1) responses based on what the mother read on the packet we provided; (2) responses based on previous experience with a jeevan jal packet or (3) based on both.

Health narratives: This task was designed to simulate the response to questioning in a health clinic. Mothers were asked to recount a health problem they, one of their children, or a relative, had. Interviewers were instructed to make mostly general questions (e.g., and then what happened?) to move the narrative along. If a mother seemed to provide too short an account or was missing a lot of important information (what steps she took, what type of medication she used, if the person recovered, etc.), interviewers asked more specific questions (e.g., did you take him to the doctor?). A maximum of 10 specific questions was allowed.

\section{References}

Bennett, L. (1983). Dangerous wives and sacred sisters. New York: Columbia University Press.

Bransford, J., Brown, A. L., \& Cocking, R. R. (1999). How people learn: Brain, mind, experience and school. Washington, DC: National Academy Press.

Chall, J. C. (1996). Stages of reading development, revised edition. Fort Worth, TX: Harcourt Brace.

Dexter, E., LeVine, S., \& Velasco, P. (1998). Maternal schooling and health-related language and literacy skills in rural Mexico. Comparative Education Review, 42, 139-162.

Diamond, I., Newby, M., \& Varle, S. (1999). Female education and fertility: examining the links. In C. Bledsoe, J. B. Casterline, J. A. Johnson-Kuhn, \& J. G. Haaga (Eds.), Critical perspectives on schooling and fertility in the developing world. Washington, DC: National Academy Press.

Glewwe, P. (1997). How does schooling of mothers improve child health? Evidence from Morocco. Living standards measurement study working paper No 128. Washington, DC: The World Bank.

Glewwe, P. (1999). Why does mother's schooling raise child health in developing countries? Evidence from Morocco. The Journal of Human Resources, 34, 124-159.

Gorman, K., \& Pollitt, E. (1997). The contribution of schooling to literacy in Guatemala. International Review of Education, 43, 283-298.

Greaney, V., Khandker, S., \& Alam, M. (1999). Bangladesh: assessing basic learning skills. Dhaka: The University Press.

Joshi, A. (1994). Maternal schooling and child health: Preliminary analysis of the intervening mechanisms in rural Nepal. Health Transition Review, 4, 1-28.
Khandke, V., Pollitt, E., \& Gorman, K. (1999). The role of maternal literacy in child health and cognitive development in rural Guatemala. Poster presented at the biennial meetings of the society for research in child development, Albuquerque, N.M., April, 1999.

LeVine, R. A., Dexter, E., Velasco, P., LeVine, S., Joshi, A., Stuebing, K., \& Tapia Uribe, M. F. (1994). Maternal literacy and health care in three countries: A preliminary report. Health Transition Review, 4, 186-191.

LeVine, R. A., LeVine, S., Richman, A., Tapia Uribe, M. F., Sunderland Correa, C., \& Miller, P. (1991). Women's schooling and child care in the demographic transition: A Mexican case study. Population and Development Review, 17, 459-496.

LeVine, R. A., LeVine, S., \& Schnell, B. (2001). Improve the women: Mass schooling, female literacy and worldwide social change. Harvard Educational Review, 71, $1-50$.

Luther, N., \& Thapa, S. (1999). Infant and child mortality in Nepal. East-West center working paper: Population series no. 105, Honolulu, Hawaii.

Pradhan, A., Aryal, R., Regmi, G., Ban, B., \& Govindaswamy, P. (1997). Nepal family health survey 1996. Kathmandu, Nepal and Calverton, Md.: Ministry of Health (Nepal), New ERA, and Macro International Inc.

Retherford, R., \& Thapa, S. (1998). Fertility trends in Nepal, 1977-1995. In: S. Thapa, S. Neidell, \& D. Dahal, (Eds.), Fertility transition in Nepal. Special issue of Contributions to Nepalese Studies, Vol. 25 (pp. 1-58).

Sharp, D.Cole, M., \& Lave, C. (1979). Education and cognitive development: The evidence from experimental research. In Monographs of the society for research in child development, Vol. 44, Nos. 1-2, Serial no. 178.

Snow, C. E. (1990). The development of definitional skill. Journal of Child Language, 17, 697-710.

Stash, S., \& Hannum, E. (2001). Who goes to school? Educational stratification by gender caste and ethnicity in Nepal. Comparative Education Review, 45, 354-378.

Stuebing, K. (1997). Maternal schooling and comprehension of child health information in urban Zambia: Is literacy a missing link in the maternal schooling-child health relationship? Health Transition Review, 7, 151-172.

Thapa, S. (1996). Infant mortality and its correlates and determinants in Nepal: A district-level analysis. Journal of the Nepal Medical Association, 34, 94-109.

Thapa, S., Neidell, S.G., \& Dahal, D.R. (Eds.) (1998). Fertility transition in Nepal. Contributions to Nepalese studies, Vol. 25, Special Issue, July 1998. Kirtipur, Nepal: Centre for Nepal and Asian Studies, Tribhuvan University.

Thomas, D. (1999). Fertility, education and resources in South Africa. In C. Bledsoe, J. B. Casterline, J. A. Johnson-Kuhn, \& J. G. Haaga (Eds.), Critical perspectives on schooling and fertility in the developing world. Washington, DC: National Academy Press.

Wagner, D. (1993). Literacy, culture and development: Becoming literate in Morocco. New York: Cambridge University Press. 